\title{
Study of Light Electric Vehicles Propulsion Solutions by Means of Finite Element Method Based Co-Simulations
}

\author{
Mircea RUBA, Loránd SZABÓ \\ Technical University of Cluj-Napoca, Romania \\ Department of Electrical Machines and Drives \\ Mircea.Ruba@emd.utcluj.ro, Lorand.Szabo@emd.utcluj.ro
}

\begin{abstract}
The paper deals with the analysis of two solutions for light electric vehicles propulsion units. The propulsion machines taken into study are the switched reluctance and variable reluctance synchronous machines. Variable reluctance machines were chosen because there are cheep and reliable machines, these being key points for such applications. The analysis is performed by means of finite element method program coupled with MATLAB-Simulink in order to simulate the machine controlled by its electronic converter. The co-simulation is chosen in order to create realistic simulation conditions for both machines. The propulsion unit in study can be used for light electric vehicles, in particular for an electric vehicle used for people with disabilities. In the paper the two possible propulsion solutions are analyzed and compared, emphasizing benefits and drawbacks for each of them. This study will help designers in future decisions to be taken when the proper solution for such applications has to be selected. The study is focused on the torque development and machines performances point of view.
\end{abstract}

Keywords-co-simulation, finite element method, comparative study, variable reluctance machines, light electric vehicles propulsion.

\section{INTRODUCTION}

Nowadays it is known that the development of eco-friendly and cheep solutions for the propulsion units of electric or hybrid vehicles became one of the most researched area in the field of electrical engineering [1].

The paper is focused on the comparison of two such solutions. One is based on the switched reluctance machine (SRM), and the other on the variable reluctance synchronous machine (VRSM). Both have passive rotors and simple stator design [2], [3]. Hence, the production costs are quite low and their reliability is highly increased compared to the machines that include permanent magnets [4].

The two machines are designed upon the same imposed data for the propulsion of a light electric vehicle used for people with disabilities.

The comparative analysis is based on the finite element methods (FEM) by using the Flux 2D software by Cedrat. In order to simulate the machines supplied from their power converter in dynamic regime the FEM based models are coupled with the MATLAB-Simulink environment. The latter handles the control of the electronic converter, while the FEM model includes the electric machine and its electronic converter circuits.

The analysis of the two proposed propulsion systems highlights both advantages and drawbacks for each of them, offering solutions for the classical problems that occur during operation of the SRM and the VRSM.

\section{The Proposed Solutions}

The starting point of this study was based on an existing wheelchair equipped with a classical DC machine.

The main parameters of the DC machine were the electric power $1.3 \mathrm{~kW}$ and the developed torque $3.5 \mathrm{~N} \cdot \mathrm{m}$. The power supply consists in two series connected batteries of $12 \mathrm{~V}$, totally of $24 \mathrm{~V}$. The maximum speed of the machine is $3400 \mathrm{r} / \mathrm{min}$, and the shaft of the machine is connected to a gearbox with 1:19 ratio. Also some space limitations are considered in order to have as small as possible electrical machine and to reach the highest power density possible.

Both electrical machines were designed taking into account the above mentioned specifications and restrictions.

\section{A. The switched reluctance machine}

The switched reluctance machine (SRM) design solution is considered to be a $6 / 4$ stator to rotor poles ratio. Lower ratios would increase a lot the torque ripples and higher ratios the cost of the machine and its electronic converter.

The sizing process [5] of the SRM needs to impose the rated current $(I)$, the number of phases $(m)$, the machine's rated power $\left(P_{2 N}\right)$, the mechanical air-gap $(g)$ the air-gap flux density in aligned position $\left(B_{\text {gmax }}\right)$, the rated speed $\left(n_{N}\right)$ and the rated torque $\left(T_{N}\right)$. All these details are given in Table I.

The design starts by sizing the mean diameter $\left(D_{g}\right)$, which has a direct influence on the torque development [6]. It depends on the rated power and speed, the number of stator and rotor poles, respectively the air-gap flux density $\left(B_{\text {gmax }}\right)$. 
TABLE I

The SRM's main specifications

\begin{tabular}{|l|c|}
\hline \multicolumn{1}{|c|}{ Parameter } & Value \\
\hline Feed voltage & $\mathrm{U}_{\mathrm{N}}=24 \mathrm{~V}$ \\
\hline Imposed current & $\mathrm{I}=80 \mathrm{~A}$ \\
\hline Output power & $\mathrm{P}_{2 \mathrm{~N}}=1.2 \mathrm{~kW}$ \\
\hline Rated torque & $\mathrm{T}=3.4 \mathrm{~N} \cdot \mathrm{m}$ \\
\hline Rated speed & $\mathrm{n}_{\mathrm{N}}=3200 \mathrm{r} / \mathrm{min}$ \\
\hline Number of stator poles & $\mathrm{Q}_{\mathrm{S}}=8$ \\
\hline Number of rotor poles & $\mathrm{Q}_{\mathrm{R}}=6$ \\
\hline
\end{tabular}

$$
D_{g}=\sqrt[3]{\frac{P_{2 N} \cdot Q_{S} \cdot k_{\sigma}}{Q_{R} \cdot \pi^{2} \cdot k_{L} \cdot \frac{n_{N}}{60} \cdot B_{g_{\max }} \cdot\left(1-\frac{1}{K_{C r}}\right) \cdot A_{S}}}
$$

where $k_{\sigma}=0.9$ is the leakage flux factor, $K_{C r}=1.9$ the Carter factor, $A_{s}=10^{4} \mathrm{~A} / \mathrm{m}$ the electrical loading and $k_{L}$ is the aspect ratio.

The stator and rotor pole pitch values, $\tau_{S}$ and $\tau_{R}$, are computed as a ratio between the mean diameter of the machine and the number of stator poles.

Function of the rotor and stator pole widths, the yokes are computed with regards to a ratio of $0.5 \div 1$ of the pole widths.

Lower yoke widths will increase the saturation, optimizing this way the machine's performance. A good compromise has to be taken into consideration for the values of the yokes [7].

The yokes of the SRM have to be deeply saturated to obtain a fast fall of the current during non conduction periods. However, consistently increased saturations need to be avoided as much as possible this way diminishing the power losses in the magnetic core and heating problems.

The stator and the rotor final dimensions are computed after sizing the coils and the shaft.

\section{1) Sizing the coils of the SRM}

Sizing the number of turns and the cross section of the wire is accomplished function of the magnetic field's distribution $H$ and the machine's geometrical dimensions. With regards to the imposed flux density in the air-gap of the machine, the magnetic field $H_{g}$ can be computed function of the air permeability $\mu_{0}$. A mean flux density can be considered for the entire magnetic circuit [8].

The number of turns per coil is defined as the ratio between the magneto-motive force and the rated current of the machine. In this case, the number of turns per coil is 6 . Selecting the proper wire function of the considered current density will help defining the slot height, finalizing the sizing of the stator segment.

Because the current in the windings is quite high, the cross section area is chosen at $11 \mathrm{~mm}^{2}$ and rectangular shaped wire was used in the building process of the machine.

In Table 2 the final dimensions of the SRM are detailed and the shape of the stator and rotor are given in Figs. 1 and 2.
TABLE II

The SRM's main geometrical dimensions

\begin{tabular}{|l|c|}
\hline \multicolumn{1}{|c|}{ Parameter } & Value \\
\hline Height of the stator pole & $\mathrm{h}_{\mathrm{pS}}=17 \mathrm{~mm}$ \\
\hline Height of rotor pole & $\mathrm{h}_{\mathrm{pR}}=8.2 \mathrm{~mm}$ \\
\hline Height of stator yoke & $\mathrm{h}_{\mathrm{jS}}=7 \mathrm{~mm}$ \\
\hline Height of rotor yoke & $\mathrm{h}_{\mathrm{jR}}=7 \mathrm{~mm}$ \\
\hline Weight of stator pole & $\mathrm{b}_{\mathrm{pS}}=10 \mathrm{~mm}$ \\
\hline Weight of rotor pole & $\mathrm{b}_{\mathrm{pR}}=11.5 \mathrm{~mm}$ \\
\hline Active stack length & $\mathrm{l}_{\mathrm{S}}=80 \mathrm{~mm}$ \\
\hline Air-gap length & $\mathrm{g}=0.1 \mathrm{~mm}$ \\
\hline Outer machine diameter & $\mathrm{D}_{\mathrm{m}}=115 \mathrm{~mm}$ \\
\hline
\end{tabular}

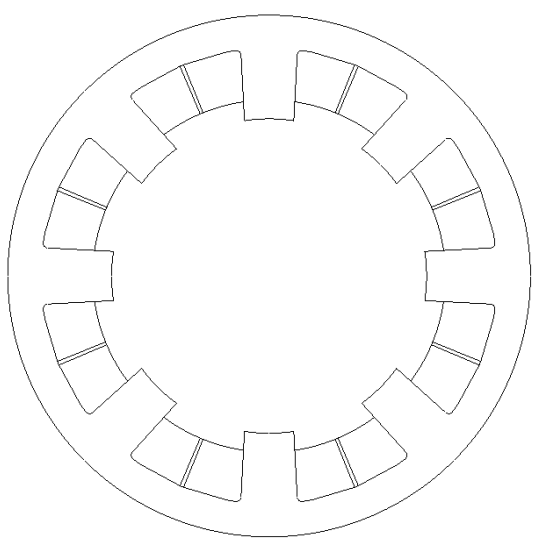

Fig. 1. The stator of SRM.

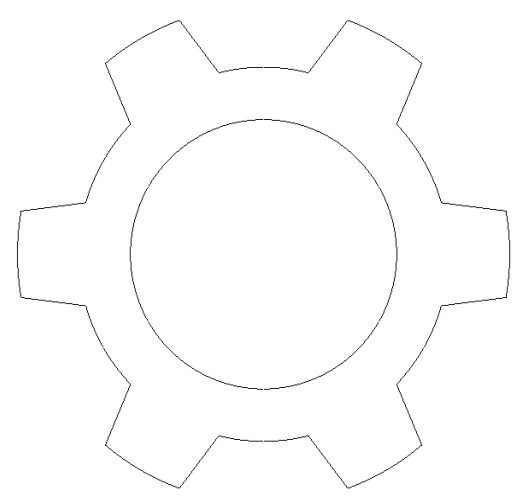

Fig. 2. The rotor of the SRM.

\section{2) The analitical expresion of the torque}

The torque developed by the machine can be analytically expressed using a simplified equation based on the MMF and the machine's main geometrical dimensions:

$$
T_{v}=k_{\text {unal }} \cdot\left(N_{f} \cdot I\right)^{2} \cdot \frac{D_{g}}{2} \cdot \mu_{0} \cdot \frac{l_{s}}{2 \cdot g_{x}}
$$

where $k_{\text {unal }}$ is a constant that takes in consideration the contribution of the magnetic flux in unaligned position and $N_{f}$ the number of turns of a phase. The equivalent airgap is $g_{x}=k_{\text {sat }} \cdot g$, where $k_{\text {sat }}$ is the aligned saturation factor for the magnetic core [9].

The developed torque, computed analytically with (2) is $3.45 \mathrm{~N} \cdot \mathrm{m}$, quite close to the desired value for the proposed SRM. The FEM model of the machine will validate the above computed value for the torque. 


\section{B. The variable reluctance synchronous machine}

The variable reluctance synchronous machine (VRSM) considered to be analysed for the present study, was rated in the same frame of specifications as the SRM above explained in detail. If for the SRM a custom made analytical breviary was used for the design process, for the VRSM special electrical machine design software was engaged (SPEED). Due to complex flux closing paths, creating a classical analytical breviary for the VRSM is quite complicated and the chance of low accuracy is present [2], [10]. Hence, using specialised software becomes helpful and also ensures the quality of the designed model.

The parameters for the VRSM in the design process were initially considered exactly the same as for the SRM.

TABLE III

The VRSM's main specifications

\begin{tabular}{|l|c|}
\hline \multicolumn{1}{|c|}{ Parameter } & Value \\
\hline Rated output power & $1.2 \mathrm{~kW}$ \\
\hline Rated speed & $3400 \mathrm{r} / \mathrm{min}$ \\
\hline Rated phase voltage & $24 \mathrm{~V}$ \\
\hline Outer diameter & $0.14 \mathrm{~m}$ \\
\hline Machine length & $0.08 \mathrm{~m}$ \\
\hline Number of phases & 3 \\
\hline Rated torque & $3.4 \mathrm{~N} \cdot \mathrm{m}$ \\
\hline
\end{tabular}

Due to the possibility of fast design process in SPEED software, initially an attempt to design a VRSM with the exact same outer dimensions as the SRM was considered (see Fig. 3).

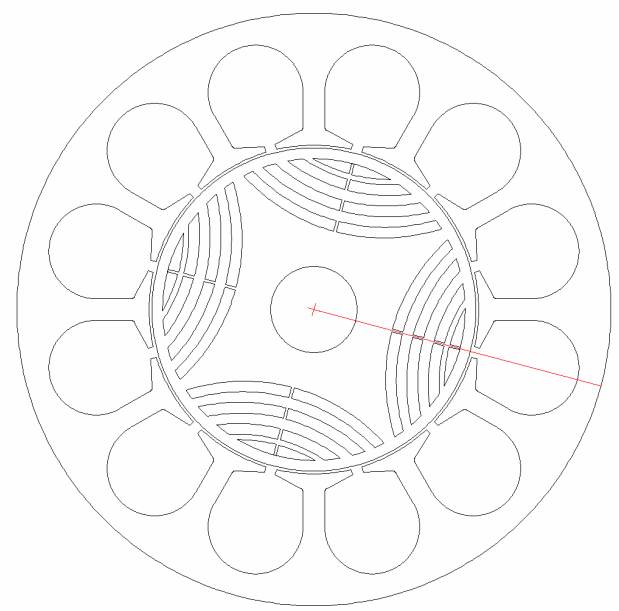

Fig. 3. The initial VRSM

Due to small dimensions and to low feeding voltage, the machine was not able to reach the desired performances. It can be seen in Fig. 3 that the number of stator slots is also low, again, due to small outer diameter. For this machine the outer diameter was imposed to $110 \mathrm{~mm}$.

Considering that in these specifications the machine is impossible to be designed/built with classical technologies and materials, the first step was to increase the outer diameter. This was enlarged to $180 \mathrm{~mm}$ in order to create space to increase the number of stator slots.
As it can be seen in Fig. 4, the number of stator slots was increased to 24 , simultaneously increasing also the MMF in the air-gap to reach the desired torque.

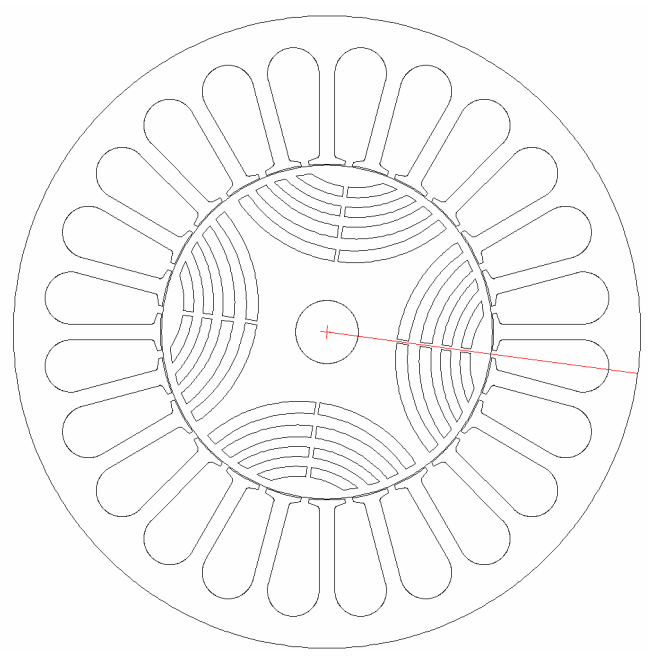

Fig. 4. The final VRSM structure

The first computations highlighted another serious problem. The back EMF in the machine is quite increased due to the rotating magnetic field of the machine. Hence, the supply voltage, $24 \mathrm{~V}$, is not high enough to increase the current of the machine to the desired value to develop the rated torque.

A first attempt to overcome this problem was to decrease the number of turns per coil from 40 to 20 and increase the phase current to obtain mainly the same MMF in the air-gap.

Performing several simulations proved that the machine is still not able to reach the desired torque value. Hence a second compromise was considered, to increase the number of turns per coil to a mid-value of 30 , and to increase the supply voltage to $48 \mathrm{~V}$. In this condition, the machine was able to reach the desired performances. Increasing the supply voltage requires adding to the power converter a boost stage to increase the voltage from 24 to $48 \mathrm{~V}$. The boosting stage however can raise the DC bus to $48 \mathrm{~V}$ just in the moments when maximum power is required from the machine.

It was already concluded that the VRSM and the SRM in the same requirements cannot be at the same dimensions.

\section{THE FEM BASED ANALYSIS}

In order to validate the two machine structures, after their analytical sizing process is considered finished, finite element method based analysis is engaged. The software employed for such computations is Flux 2D of Cedrat. The FEM study for each machine represents the creation of a model that combines geometrical, electrical and mechanical problems in order to simulate the behaviour of the machine in several operating conditions.

The geometrical aspects of any FEM model starts from setting the points of the machine structure, unifying them using lines and by this, creating closed surfaces. Each surface is characterised by a mobile or fixed mechanical 
set, a certain material and an electrical circuit, in the case of the coils.

For proper simulations, the model is divided in many small elements, forming the mesh of the geometry. Denser mesh is required for better accuracy of the results, but in the same time, but this means longer the computation times. Normally the computation time of such models can vary between 4 to 10 hours.

\section{A. The FEM model of the switched reluctance machine}

In the above fragments, some general guidelines reflecting the FEM model of any electrical machines were detailed. As each machine has its own particularities, the SRM model is composed of 8 stator poles and 6 rotor poles. The geometry was creating function of the specifications detailed in Table II.

After creating the points, lines, surfaces and all the physical requirements for a complete model, an automatic mesh is engaged in order to finalize the machine model (see Fig. 5).

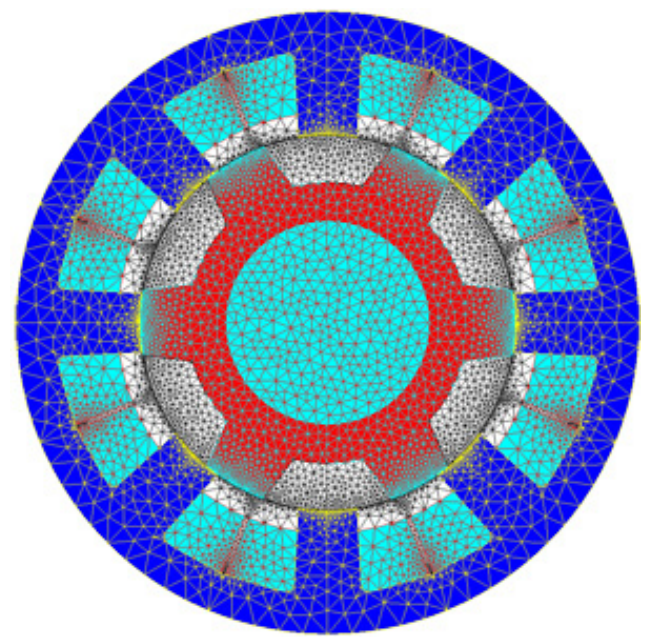

Fig. 5. The SRM model with mesh

The electrical circuit attached to the machine model is presented in detail in Fig. 6.

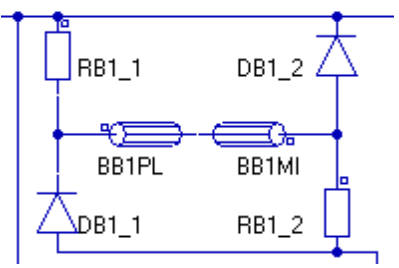

Fig. 6. The electrical circuit for each phase of the machine

As it can be seen, each phase is composed of two coil components and the phase is fed via ah half $\mathrm{H}$-bridge. The power switches are here replaced with resistances and their values are controlled from Simulink to simulate the operation of the transistors (ON and OFF states).

As stated above, the simulation indeed needs to be couple the FEM model of the machine with the MATLAB-Simulink environment, in order to perform the control of the currents function of the actual current in the machine and the rotor position. These currents are controlled using hysteresis comparators, a classical method for the SR machine. The coupling is accomplished using the dedicated Flux-to-Simulink technology, existing in the Simulink library [11].

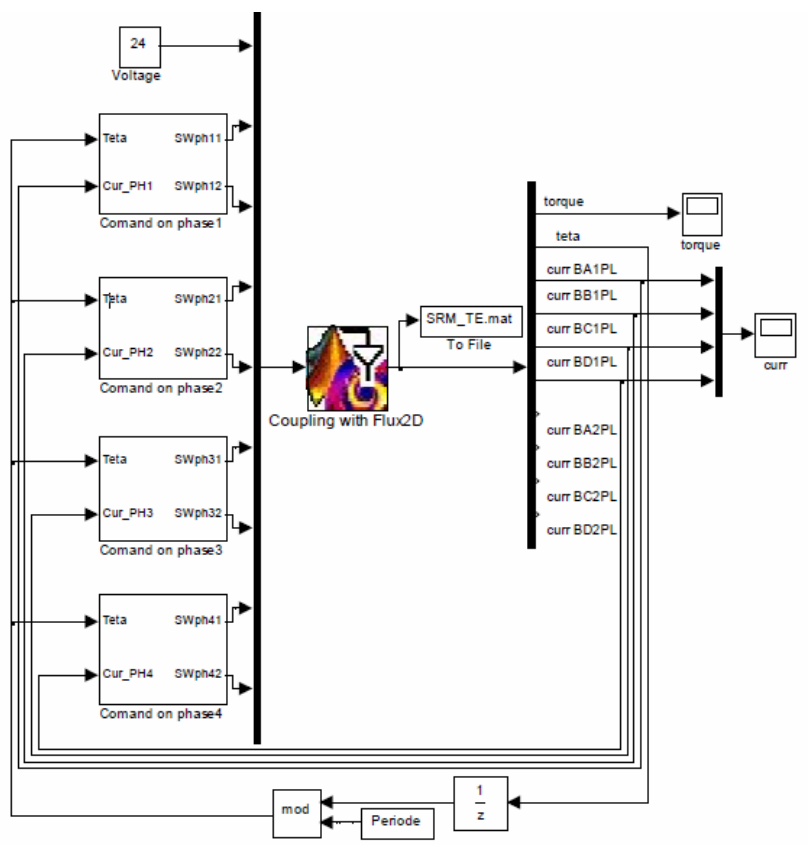

Fig. 7. The Flux to Simulink coupling model for the SRM

The coupled model performs time stepping simulations. Hence, the Simulink model sends the signals to the resistors modelling the power switches function of the actual currents and the rotor position, and the FEM model of the machine, computes the influence of these currents, in the machine, returning their actual value and the developed torque. Such simulations are quite close to the real behaviour of the machine and return a realistic image about the field and flux density distribution in the core, together with the value of the developed torque.

The flux density maximum values do not cross hazardous values (see Fig. 8); hence, the machine will operate in normal conditions without overheating problems or core saturation issues.

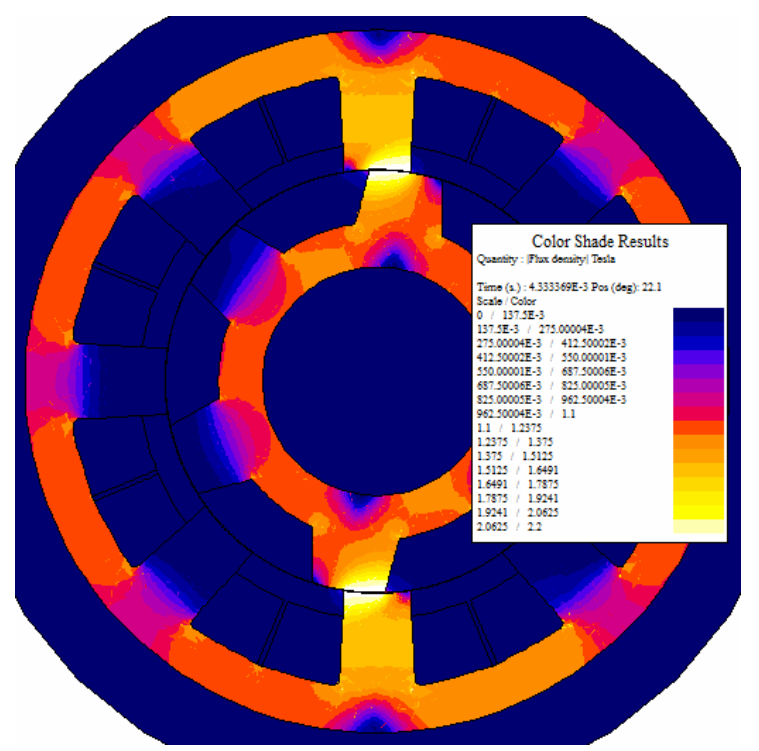

Fig. 8. The flux density distribution in the SRM 
The developed torque function of the currents in the 4 phases of the machine can be seen in Fig. 9.
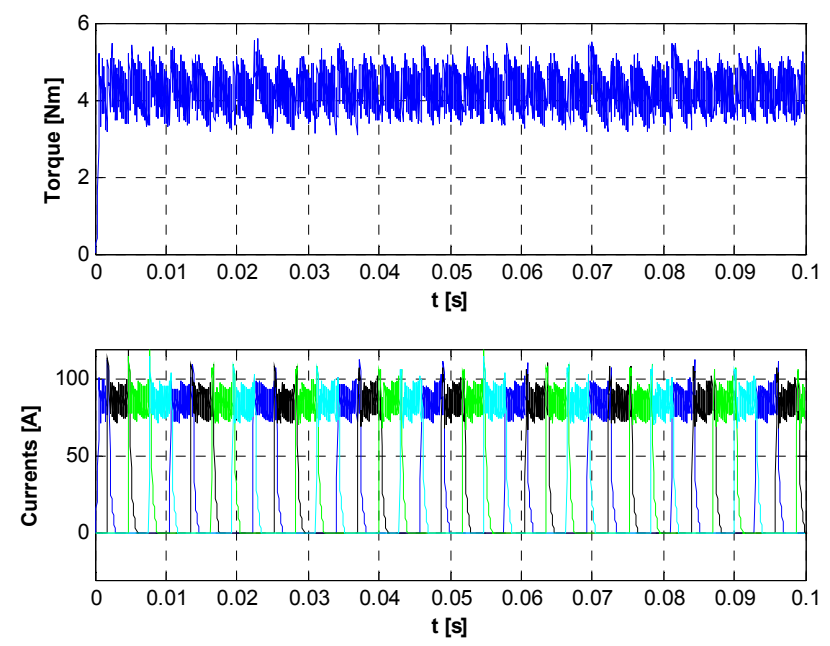

Fig. 9. The torque (upper) and the currents in the 4 phases (lower)

As seen in Fig. 9, the mean torque is at about $3.8 \mathrm{~N} \cdot \mathrm{m}$, more than desired, hence the machine is validated from all the points of view. The simulations were performed at the rated speed of $3400 \mathrm{r} / \mathrm{min}$ and at rated current of $80 \mathrm{~A}$.

The efficiency of the SRM computed at rated power is 0.72 , quite satisfactory considering that SRMs has low efficiency at small powers.

\section{B. The FEM model of the variable reluctance synchronous machine}

Based on the same work flow as described earlier in the paper, the FEM model for the VRSM was created in order to validate the design performed by means of the SPPED program.

In Fig. 10 the mesh of the VRSM model is depicted.

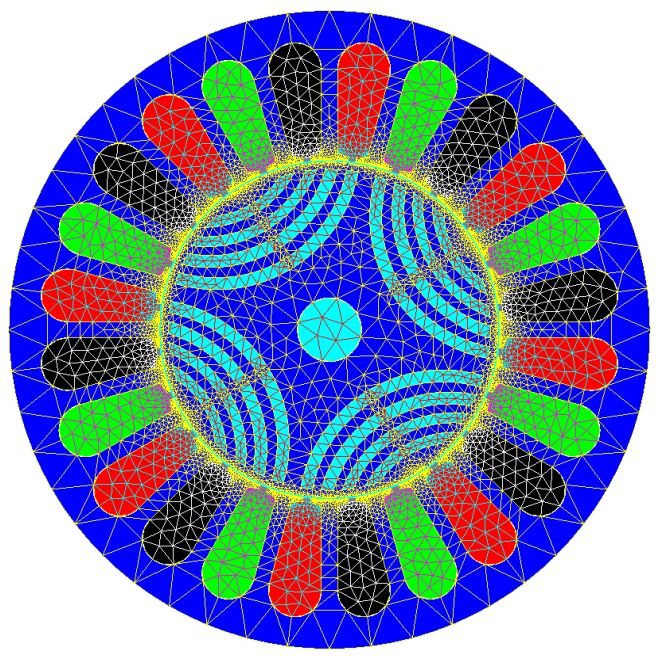

Fig. 10. The VRSM model with mesh

In Fig. 11 the electrical circuit for one phase of the machine is given. It can be seen that now, for each phase of the machine is a complete H-bridge is needed. Its circuit model is composed of 4 resistors to simulate the power switches.

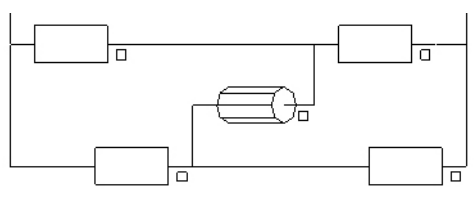

Fig. 11. The VRSM electrical circuit

Also in this case their control is solved by coupling the FEM model with the MATLAB-Simulink environment. Three-phase sinusoidal currents controlled via hysteresis comparators are imposed (see Fig. 12).

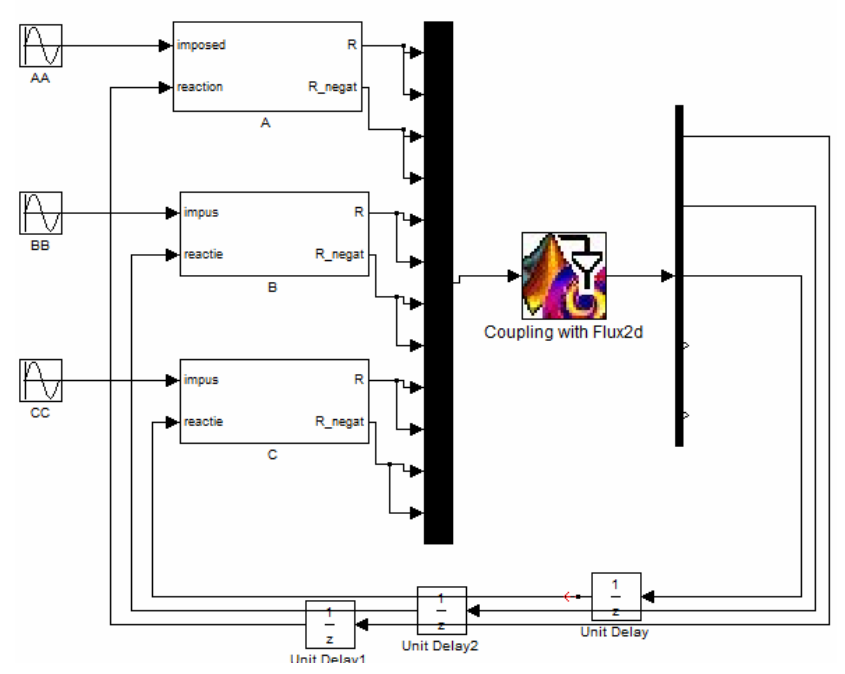

Fig. 12. The Flux to Simulink coupling model for the VRSM

By this, modelling the VRSM reaches realistic behaviour as the currents in the machine are obtained by switching the DC bus voltage like in a real application. The currents are controlled function of the rotor position, imposing a shifting between the rotating field and the actual rotor position of 45 degrees. This is known to be a classical method to obtain maximum torque for the VRSM.

Analyzing Fig. 13, it can be seen that the flux density in the machine's core reaches satisfactory values without any highly saturated regions [12]. This needs to be a good compromise in order to optimize the power density of the machine, reaching good performances and lower dimensions and implicitly lower weight for the structure.

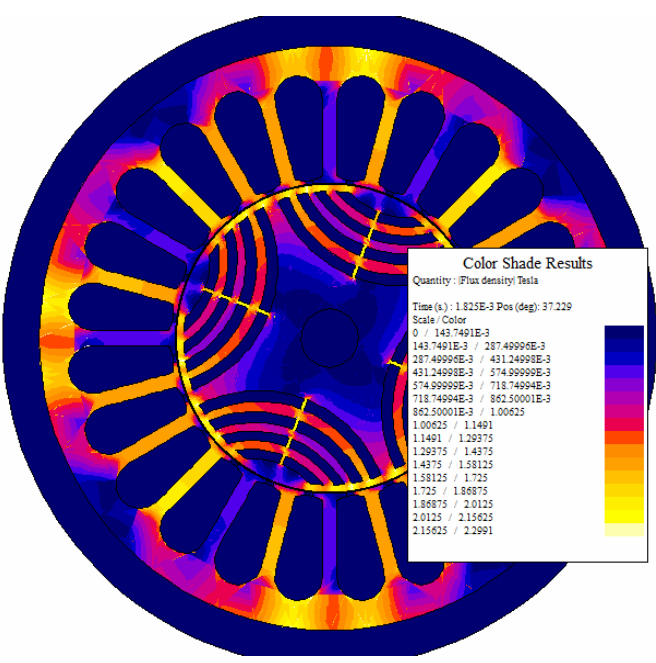

Fig. 13. The flux density distribution in the VRSM 
In Fig. 14, the developed torque of the VRSM function of the phase currents is depicted. It can be seen that the mean torque is about $3.5 \mathrm{~N} \cdot \mathrm{m}$ as expected; hence the machine reaches its desired parameters.
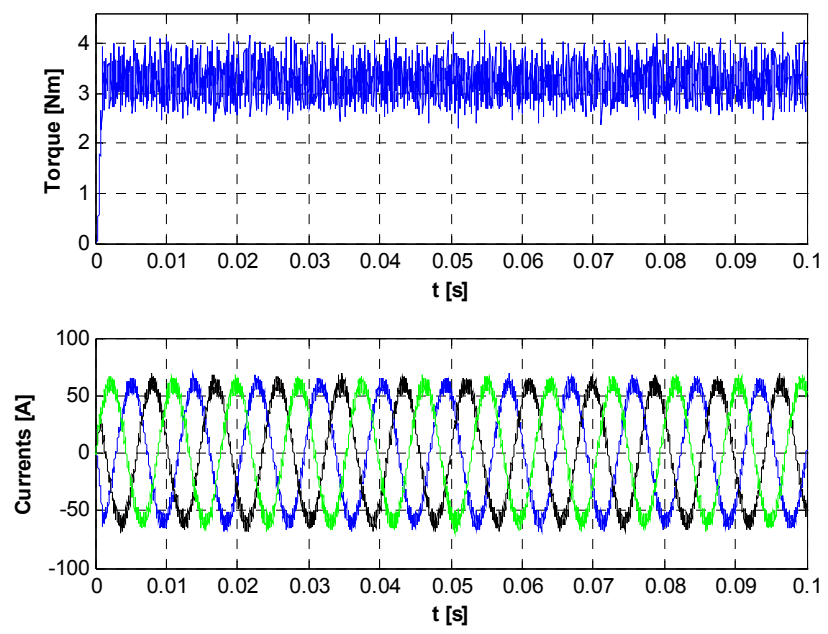

Fig. 14. The torque and the 3 phase currents of the VRSM

The peak value for the currents is about $60 \mathrm{~A}$ and their shape is close to sinusoidal, having some switching harmonics. This is natural as long as the machine is controlled either PWM or hysteresis current control strategies.

The efficiency of the machine is about 0.67 , a bit lower than that of the SRM. It is known that the VRSM's efficiency increases with the power of the machine, and to lower power values lower efficiencies correspond.

\section{CONCLUSIONS}

Variable reluctance machines are perfect candidates for the propulsion of light electrical vehicles, like the electric wheelchair in study.

In the advanced simulations based study two electrical machines were taken into consideration for this purpose: the SRM and the VRSM. To serve a correct comparison, both machines were designed upon the same imposed data and restrictions.

The two designed machines dynamic simulation for the validation of the design procedure was performed via an advanced co-simulation technique, based on coupling a precise FEM based model of the machine and its power converter with the control system simulation program built up in Simulink.

The proposed simulation technique proved to be very efficient in the in depth analysis and comparison of the two electrical machines and their drives.

Future works include the building up of the laboratory models of the two designed machines, and the performing of a comparison study based on results obtained by means of measurements.

\section{ACKNOWLEDGMENT}

This paper was supported by the Post-Doctoral Programme POSDRU/159/1.5/S/137516, project cofunded from European Social Fund through the Human Resources Sectorial Operational Program 2007-2013 and by the Romanian Executive Agency for Higher Education, Research, Development and Innovation Funding (UEFISCDI) under the Automotive Low-Noise Electrical Machines and Drives Optimal Design and Development (ALNEMAD) Joint Applied Research Project (PCCA) in the frame of "Partnerships" projects (PN II - National Plan for Research, Development and Innovation).

\section{REFERENCES}

[1] D. Fodorean, S. Giurgea, A. Djerdir, A. Miraoui, "Numerical approach for optimum electromagnetic parameters of electrical machines used in vehicle traction applications," Energy Conversion and Management, vol. 50, no. 5, pp. 1288-1294, 2009.

[2] G. Henneberger, I.A. Viorel, Variable Reluctance Electrical Machines. Aachen (Germany): Shaker Verlag, 2001.

[3] A. Arkadan, N. Al-Aawar, A. Hanbali, "Design Optimization of SynRM Drives for HEV Power Train Applications," in Proceedings of the Electric Machines \& Drives Conference (IEMDC '07), 2007, pp. 810-814.

[4] D. Dorrell, L. Parsa, I. Boldea, "Automotive electric motors, generators and actuator drive systems with reduced or no permanent magnets and innovative design concepts," IEEE Transactions on Industrial Electronics, vol. 61, no. 10, pp. 56935695, 2014.

[5] M.N. Anwar, I. Husain, A.V. Radun, "A comprehensive design methodology for switched reluctance machines," IEEE Transactions on Industry Applications, vol. 37, no. 6, pp. 16841692, 2001.

[6] H. Hannoun, M. Hilairet, C. Marchand, "Comparison of instantaneous and average torque control for a switched reluctance motor," in Proceedings of the IEEE International Symposium on Industrial Electronics (ISIE '2008), Cambridge (U.K.), 2008, pp. 675-680.

[7] R. Krishnan, R. Arumugan, J. Lindsay, "Design procedure for switched-reluctance motors," IEEE Transactions on Industry Applications, vol. 24, no. 3, pp. 456-461, 2002.

[8] T. Raminosoa, B. Blunier, D. Fodorean, A. Miraoui, "Design and optimization of a switched reluctance motor driving a compressor for a PEM fuel-cell system for automotive applications," IEEE Transactions on Industrial Electronics, vol. 57, no. 9, pp. 29882997, 2010.

[9] M. Ruba, D. Fodorean, "Design, analysis and torque control of low voltage high current SRM for small automotive applications," in Proceedings of the IEEE Region 8 EUROCON Conference (EUROCON '2013), Zagreb (Croatia), 2013, pp. 1498-1503.

[10] R.R. Moghaddam, F. Magnussen, C. Sadarangani, "Novel rotor design optimization of synchronous reluctance machine for high torque density," in Procedings of the 6th IET International Conference on Power Electronics, Machines and Drives (PEM '2012), Bristol (UK), 2012, pp. 32-38.

[11] L. Szabó, M. Ruba, "Using co-simulations in fault tolerant machine's study," in Proceedings of the 23rd European Conference on Modelling and Simulation (ECMS '2009), Madrid (Spain), 2009, pp. 756-762.

[12] K.C. Kim, "Magnetic saturation effect on the rotor core of synchronous reluctance motor," Journal of Electrical Engineering \& Technology, vol. 6, no. 5, pp. 634-639, 2011. 